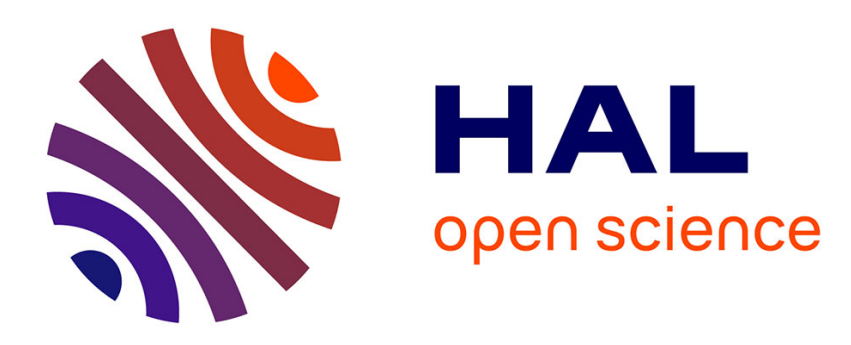

\title{
A time-of-flight spectrometer for elastic neutron scattering on powdered samples
}

\author{
G. Roult, J.L. Buévoz
}

\section{To cite this version:}

G. Roult, J.L. Buévoz. A time-of-flight spectrometer for elastic neutron scattering on powdered samples. Revue de Physique Appliquée, 1977, 12 (4), pp.581-590. 10.1051/rphysap:01977001204058100 . jpa-00244212

\section{HAL Id: jpa-00244212 https://hal.science/jpa-00244212}

Submitted on 1 Jan 1977

HAL is a multi-disciplinary open access archive for the deposit and dissemination of scientific research documents, whether they are published or not. The documents may come from teaching and research institutions in France or abroad, or from public or private research centers.
L'archive ouverte pluridisciplinaire HAL, est destinée au dépôt et à la diffusion de documents scientifiques de niveau recherche, publiés ou non, émanant des établissements d'enseignement et de recherche français ou étrangers, des laboratoires publics ou privés. 


\author{
Classification \\ Physics Abstracts \\ 7.114

\section{A TIME-OF-FLIGHT SPECTROMETER FOR ELASTIC NEUTRON SCATTERING ON POWDERED SAMPLES (*)}

\author{
G. ROULT and J. L. BUÉVOZ (**) \\ Laboratoire de Diffraction Neutronique, \\ Département de Recherche Fondamentale \\ Centre d'Etudes Nucléaires de Grenoble \\ $85 \mathrm{X}$ Centre de Tri \\ 38041 Grenoble Cedex, France
}

(Reçu le 28 juin 1976, accepté le 29 novembre 1976)

\begin{abstract}
Résumé. - Nous décrivons un spectromètre à temps de vol spécialement conçu pour des études d'échantillons polycristallins dans un environnement complexe, tel que cellule haute pression (jusqu'à $35 \mathrm{kbars}$ ) et four haute température (jusqu'à $2500^{\circ} \mathrm{C}$ ). Un chopper statistique est utilisé pour diminuer le bruit de fond indépendant du temps provenant d'un important flux de neutrons épithermiques dans le faisceau incident. Les fentes du chopper sont réparties selon une séquence pseudo-aléatoire de registre à décalage à contre-réaction binaire de 511 éléments. La bouffée élémentaire de neutrons a $8 \mu$ s de large. La géométrie a été optimisée pour obtenir une haute résolution $\frac{\Delta d}{d}$ de $0,75 \%$ pour $d=1 \AA$ et $0,4 \%$ pour $d=3 \AA$. Les affinements de structure sur des échantillons tests de structure simple $\left(\mathrm{UO}_{2}\right)$ ont donné des facteurs de confiance $R$ de $1.3 \%$ comparables à ceux obtenus avec le goniomètre à haute résolution (longueur d'onde fixe) D1A de l'Institut LaueLangevin.
\end{abstract}

\begin{abstract}
A time-of-flight spectrometer especially built for the study of powdered samples with complex surroundings, such as a high-pressure cell (up to $35 \mathrm{kbars}$ ) and a high-temperature furnace (up to $2500{ }^{\circ} \mathrm{C}$ ) is described. A correlation chopper is used to decrease the time-independent background due to the high epithermal flux in the incoming beam. The chopper slots are distributed according to a pseudo-random binary feedback shift register sequence of 511 elements, the elementary neutron pulse being $8 \mu \mathrm{s}$ in width. The geometry has been optimized in order to reach a high resolution : $\frac{\Delta d}{d}$ values of $0.75 \%$ at $d=1 \AA$ and $0.4 \%$ at $d=3 \AA$ are obtained. Structure refinements on test samples with simple structure $\left(\mathrm{UO}_{2}\right)$ give a reliability factor $R$ of $1.3 \%$ which compares fairly well with the results of the high resolution fixed-wavelength goniometer, D1A at the Institut Laue-Langevin.
\end{abstract}

1. Introduction. - The time-of-flight method, as it has been developed by Brugger et al. [1], [2] and Buras [3], is very well adapted for neutron diffraction experiments when the sample surrounding is complex. In particular, it is the best method for high pressure and high temperature work.

The spectrometer was placed on a radial beam of the Melusine $8 \mathrm{MW}$ light-water reactor of the Centre d'Etudes Nucléaires de Grenoble. The thermal flux in the incoming beam is $6.4 \times 10^{7} \mathrm{n} \mathrm{cm}^{-2} \mathrm{~s}^{-1}$. The ratio of epithermal over thermal fluxes being 0.085 , the use of a Fermi type chopper, or a chopper similar

(*) This work is a part of the thesis of J. L. Buévoz (1975) $N^{\circ}$ C. N. R. S. Ao 11644, Université de Grenoble, France.

(**) Now at Institut Laue-Langevin 156X Centre de Tri, 38042 Grenoble Cedex, France. to that of Brugger et al. [1], [2] would have involved such a high time-independent background that intensity measurements of diffraction peaks would have been inaccurate.

The correlation chopper, as developed by Gompf et al. [4], by increasing the ratio of diffraction peaks over background was the only way to solve the problem. This new kind of chopper was very promising, as shown by Sköld [5], for elastic scattering on powdered samples. In order to deconvolute the observed pattern, a matrix formalism has been developed [6,] [7], [8], allowing the analysis of a real correlation chopper experiment with all its imperfections.

2. The time-of-flight method. - In a conventional fixed-wavelength goniometer, a monochromatic wave- 
length $\lambda$ falls on the sample. Diffracted neutrons are then counted with respect to the Bragg angle $\theta$ by means of a detector-scan. The Bragg equation $\lambda_{0}=2 d$ $\sin \theta$, for a given $d$-spacing of the sample, is satisfied at an angle $\theta$.

In time-of-flight experiments, all the wavelengths of the thermal maxwellian spectrum $i(\lambda)$ are used. Detectors are at a fixed angle $\theta_{0}$ and, for a given $d$-spacing, the Bragg equation is satisfied for a wavelength $\lambda$.

A chopper emits a polychromatic neutron pulse of width $\Delta T$, at each revolution. An electronic signal $t_{0}$ is associated with each neutron pulse, and the diffracted neutrons are detected from this time, $t_{0}$, according to their time of arrival at the detectors. They are then stored in consecutive channels of width $\Delta t$ of a multi-channel analyser. So, neutrons in channel $N$ correspond to a time-of-flight $N \Delta t$ along the flight path $L_{0}$ between chopper and detectors. By means of de Broglie's law $\left(t=\frac{h}{m L_{0}} \lambda\right)$ this is equivalent to a measurement of wavelengths. A $d$-spacing is related to channel $N$ (the origin being at the middle of a channel) by the relation :

$$
\begin{aligned}
d=\frac{h}{2 m L_{0} \sin \theta_{0}}\left[(N-0.5) \Delta t+t_{\mathrm{R}}\right]= \\
=\frac{(N-0.5) \Delta t+t_{\mathrm{R}}}{C}
\end{aligned}
$$

where $h$ is the Planck constant, $m$ the neutron mass and $t_{\mathrm{R}}$ an instrumental delay.

Constants $C$ and $t_{\mathrm{R}}$ are determined by calibration using test samples ( $\mathrm{Si}, \mathrm{Ge}$ or diamond) whose parameters are well known.

The resolution, in elastic time-of-flight, has been studied by Buras [9] and Holas [10]. The general expression is :

$$
\frac{\Delta d}{d}=\left(\frac{A^{2}}{C^{2} d^{2}}+B^{2}\right)^{1 / 2}
$$

Constant $A$ includes the widths $\Delta T$ and $\Delta t$ for the neutron pulses and the analysing channels respectively, and $B$ includes geometrical terms : flight path uncertainties, chopper window width, sample and detectors sizes, beam divergency. Constants $A$ and $B$ are also measured by calibration of the spectrometer.

The integrated intensity of a diffraction peak, [1], [2], [8], [111, is given by :

$$
I_{0} \propto j \cdot i(\lambda) \cdot \lambda^{4}\left|F_{h k l}\right|^{2} \cdot A(\lambda) \cdot E(\lambda)
$$

where :

- $j$ is the multiplicity of reflection $(h k l)$. beam.

- $i(\lambda)$ is the wavelength distribution in the incoming

- $F_{h k l}$ is the structure factor of reflection $(h k l)$.

- $A(\lambda)$ is the sample absorption.

- $E(\lambda)$ is the detector efficiency.
3. Description of the spectrometer. - 3.1 BASIC CONSIDERATIONS. - The basic characteristics of the spectrometer are a compromise between technical considerations (especially machining and strength of materials) and the necessity of good resolution and intensity.

a) The flight path is 4 meters maximum because of space limitations in the Melusine reactor hall.

b) Only neutrons of wavelength between 0.5 and $4.5 \AA$ have a sufficient flux to give rise to diffraction peaks with measurable intensity.

c) The mechanical strength of materials limits the speed and the diameter of the disc.

d) Short neutron pulses are needed to reach a good resolution.

e) A large chopper window is necessary to obtain sufficient luminosity.

f) A correlation chopper is needed to eliminate high time-independent background.

The first two points give the chopper period and speed respectively of $4 \mathrm{~ms}$ and $15,000 \mathrm{rpm}$, to avoid overlapping of fast and slow neutrons along the 4 meter flight path.

Point $\mathrm{c}$ gives a diameter of $51 \mathrm{~cm}$ for an aluminium alloy disc (the peripherical speed being $400 \mathrm{~m} / \mathrm{s}$ ).

Then a binary feedback shift-register sequence of 511 elements $\left(N \doteq 2^{9}-1\right)$ was selected, with a neutron pulse of $8 \mu$ s width.

Two other speeds of 7,500 rpm and 12,000 rpm are also available, giving less resolution and also less wear of the chopper bearings.

Table I gives the chopper characteristics.

\section{TABLE I}

Low speed

$\begin{array}{ccc}\Delta T \mu \mathrm{s} & T \mu \mathrm{s} & \Omega \mathrm{rpm} \\ \overline{16} & 8 \overline{176} & 7338.551 \\ 10 & 5110 & 11741.683 \\ 8 & 4088 & 14677.103\end{array}$

High speed

3.2 The Flight PATH. - The inpile collimator is $1.35 \mathrm{~m}$ long and $5 \mathrm{~cm}$ high. The slit is $4 \mathrm{~mm}$ wide at the core side and $2 \mathrm{~mm}$ at the chopper side. The flight path $L_{0}$ is in two parts : a length $L$ between chopper and sample and 1 between sample and detectors. The resolution term concerning sample size [8], [9] may be minimized if $l=0.395 L_{0}$. Values of $l=1.5 \mathrm{~m}$ and $L=2.5 \mathrm{~m}$ were selected in this way.

The spectrometer is placed on a radial beam which necessitates thick biological shielding around the chopper and along the whole flight path. $50 \mathrm{~cm}$ thick concrete is used. There are also polyethylene, cadmium and boron around the chopper. The detector shielding, behind the concrete, is made of $9 \mathrm{~cm}$ polyethylene and $3 \mathrm{~mm}$ borated resin (Fig. 1). 


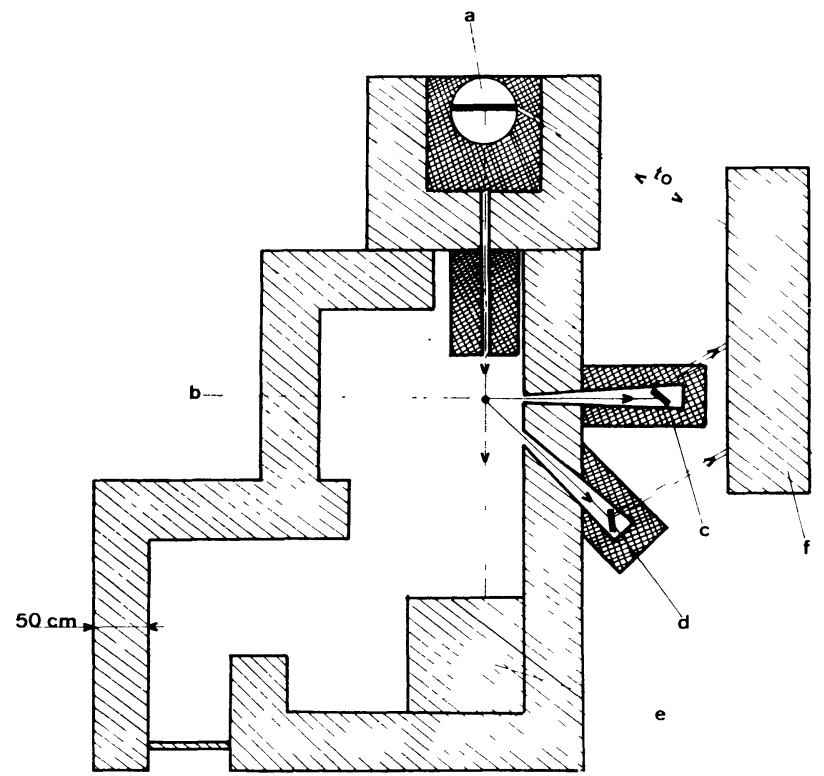

FIG. 1. - Schematic drawing of the spectrometer : a) chopper, b) sample, c) $90^{\circ}$ detectors, $d$ ) $45^{\circ}$ detectors, $e$ ) beam catcher, $f$ ) electronics ; polyethylen, $\mathbb{Q}$ concrete

3.3 THE CHOPPER. - The whole chopper (disc and motor) is enclosed inside an evacuated aluminium box. The thin, horizontal axis, chopper disc [8] is made of $\mathrm{AU}_{4} \mathrm{SG}$ aluminium alloy, forged and annealed at $125^{\circ} \mathrm{C}$, in order to obtain homogeneous mechanical caracteristics. Its diameter is $51 \mathrm{~cm}$ and it weights $8 \mathrm{~kg}$. Its shape is close to the constant stress profile [12] with $5 \mathrm{~mm}$ thickness at the periphery. The central part, which is thicker and subject to less stress, is used to fix the rotation axis and to machine the balancing holes.

At the disc periphery, radial cavities, $55 \mathrm{~mm}$ in height and $2 \mathrm{~mm}$ in depth are machined on a mean diameter of $450 \mathrm{~mm}$. They are filled with absorber and correspond to the zero elements of the shiftregister sequence. They appear in white in figure 2. The absorber is a $\mathrm{Gd}_{2} \mathrm{O}_{3}-$ Epoxy resin mixture with the following proportions in weight :

$\begin{array}{ll}\text { Epikote } 828 & : 28.5 \% \\ \text { Epikure } 104 & : 14.3 \% \\ \mathrm{Gd}_{2} \mathrm{O}_{3} \text { powder }: 52.2 \%\end{array}$

A 3 phase synchronous hysteresis motor is used in order to obtain good speed accuracy. The chopper is first started by means of a variable frequency generator and at synchronism connected to a fixed stabilized frequency coming from the quartz, which is used for all the electronics. The power supply voltage is then diminished to adjust the motor torque to the frictional torque in order to minimize losses in the rotor and avoid overheating which is a problem under vacuum.

The motor and disc axes are aligned at construction. The each terminate by 4 steel fingers. The connection

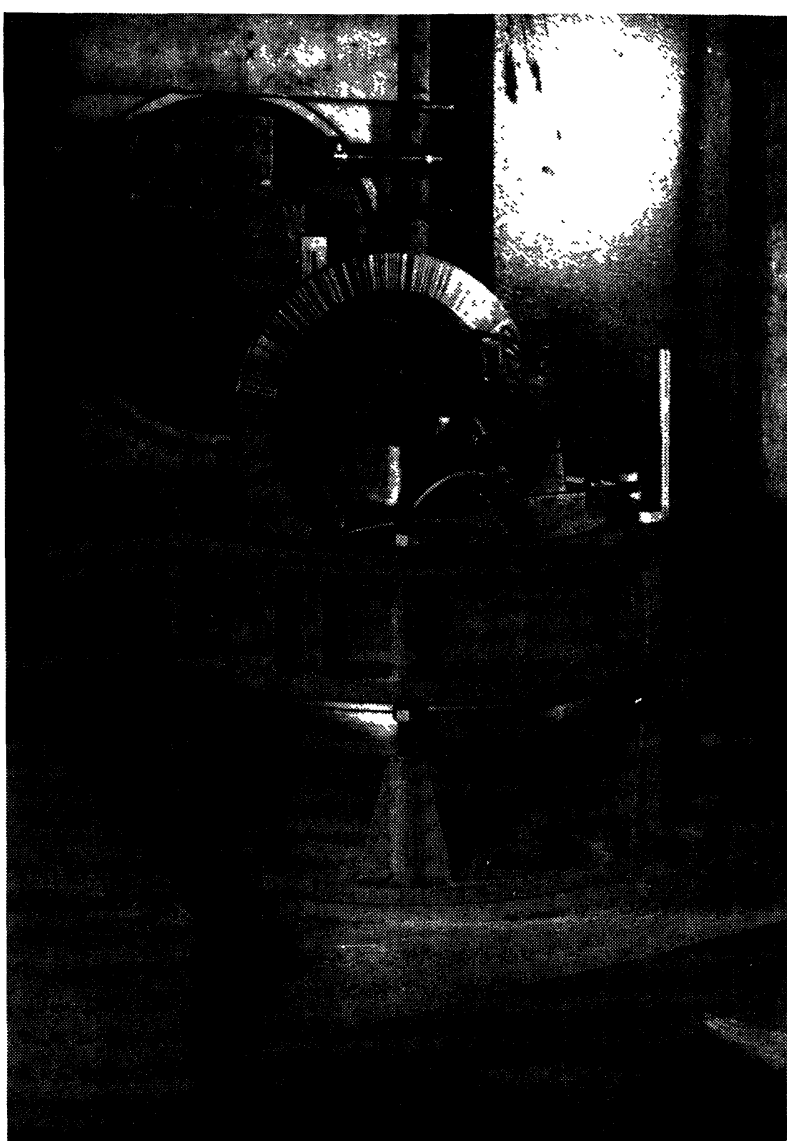

FIG. 2. - The chopper. The white parts correspond to the epoxy- $\mathrm{Gd}_{2} \mathrm{O}_{3}$ absorber.

between motor and disc fingers is achieved by means of copper tubes calculated to break in case of bearing seizure.

High precision ball-bearings (BARDEN 102 HDLC), lubricated dy grease, are used. Thermostated water cooling keeps the bearings at constant temperature $\left(40{ }^{\circ} \mathrm{C}\right)$, controlled by means of thermistors. Safety circuits stop the chopper if overheating, vacuum leakage or mechanical vibrations occur. The normal amplitude of vibration is $0.4 \mu$ at $15,000 \mathrm{rpm}$.

3.4 DeteCtors AND DATA-ACQUisition. - Two diffraction angles are used at $2 \theta=90^{\circ}$ and $45^{\circ}$. In the case of complex sample surroundings, the $90^{\circ}$ angle eliminates the diffraction of the sample container, $60 \%$ of the total sample volume being used in diffraction. Also, at this angle the Debye-Scherrer cone is reduced to a plane, and the positioning of the detector is easier.

The detectors must have high efficiency for intensity reasons and must be thin to minimize flight path uncertainties. These conditions are fulfilled by $\mathrm{He}^{3}$ detectors ( 8 bars pressure) of $9 \mathrm{~mm}$ inner diameter (10 $\mathrm{mm}$ outer diameter) and $125 \mathrm{~mm}$ active length (200 $\mathrm{mm}$ total length). In order to increase intensity they are arranged in groups of 8 fixed on an arm set 
tangentially to a circle by an optical autocollimation method. As there are 8 detectors side by side, they cover a large range $\Delta \theta$ about $\theta_{0}$ resulting in an important loss of resolution. This can be overcome using the focusing principle [9], [10] i. e. by canting the detectors, with respect to the mean diffracted beam at angle $\theta_{0}$, in order to set them on the constant time-offlight curve $\left(L_{0} \sin \theta_{0}=\right.$ constant $)$.

The maximum wavelength in the beam being $4.5 \AA$, d-spacings up to $3.2 \AA$ and $5.9 \AA$ can be measured at $90^{\circ}$ and $45^{\circ}$ respectively. At $90^{\circ}$ (Fig. 3) there are 3 groups of detectors with focusing angle $533^{\circ}$, covering $4 \%$ of the Debye-Scherrer cone.

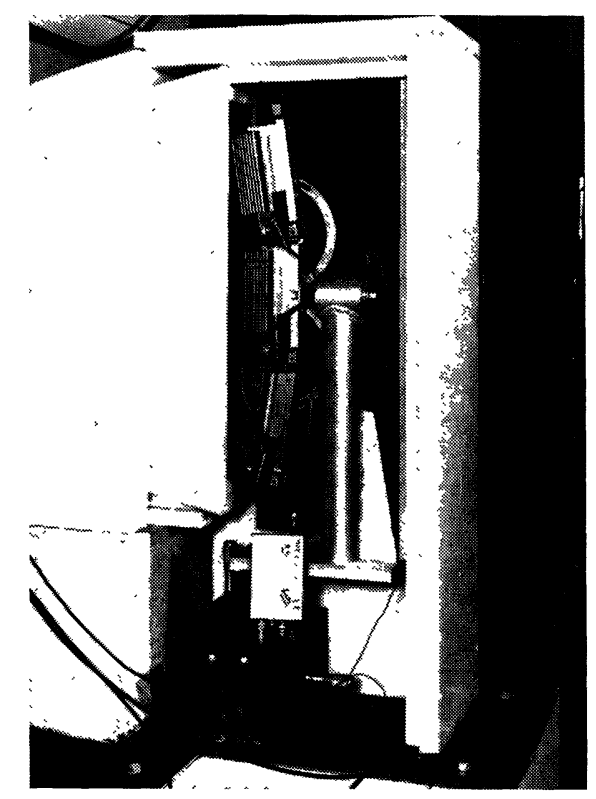

FIG. 3. $-90^{\circ}$ detector banks.

At $45^{\circ}$ only 2 groups cover $3.7 \%$ of the cone, with focusing angle $70.7^{\circ}$. There is less resolution and with the same collimation as for $90^{\circ}$, diffraction peaks from the sample container can be seen.

The neutrons detected give rise to an electronic pulse which is time encoded with respect to the socalled « $t_{0}$ " signal given by the chopper at each revolution. This signal is obtained by means of a light source illuminating the disc side which is blackened, except for a small portion acting as a mirror. At each revolution a phototransistor detects the reflected light and gives rise to the $" t_{0} »$ signal. The encoded neutron pulses are stored in the channels of a multichannel analyser (INTERTECHNIQUE BM96).

3.5 DECONVOLUTION OF THE OBSERVED DIFFRACTION PATTERN. - Using a correlation chopper, the observed diffraction pattern is the $Z$ function defined in [6], [7]. It is the superposition of $\frac{N+1}{2}=256$ elementary patterns shifted in the same way as the +1 elements of the shift-register sequence. The elementary pattern (the $F$ function) is then obtained by calculating the expression :

$$
\begin{aligned}
& F_{k}=\frac{4}{m(N+1)} \sum_{i=0}^{m N-1} a_{i-k} Z_{i}-\frac{2}{m(N+1)} \sum_{i=0}^{m N-1} Z_{i} \\
& (k=0 \ldots m N-1)
\end{aligned}
$$

where $m$ is the number of analysing channels during the duration $\Delta T$ of the elementary neutron pulse, $N$ the number of elements in the shift register sequence, and $a_{i}$ being 0 or +1 .

Deconvolution is performed at the end of the data acquisition by means of a computer (INTERTECHNIQUE MULTI 8) associated to a $50 \mathrm{~K}$ magnetic disc. A value of $m=2$ was selected and gives sufficient definition of the peak profiles. As shown in [6], theoretical values of the $\left\{a_{i}\right\}$ rectangular sequence are used. With these conditions 4 minutes are needed for the complete calculation.

4. Spectrometer performance. - A disc with one slot, similar to the elementary slot of the correlation chopper, has been constructed, in order to test the electronics and the chopper power supply. In figure $4 a$ a Silicon pattern is shown, obtained with this one slot disc, and figure $4 b$ is the result of a run with the same sample and geometry but with the correlation disc. In this latter case, the increase of statistical accuracy is obvious, and peaks have a better profile definition, especially the 111 peak. The time-independent background is 25 , compared to 6600 with the single slot disc.It is divided by $\frac{N+1}{2}=256$ as foreseen.

The negative peaks [7], coming from the wavelengthdependent transmission function of the chopper are very well defined in the Iron pattern of figure $5 a$. They are at a distance of 473 channels from the diffraction peaks. They can be suppressed as shown in [7] by calculating a diffraction function $F_{k}^{\prime}$ from the observed $F_{k}$

$$
\begin{aligned}
F_{k}^{\prime} & =F_{k}+0.0158 \lambda_{k} F_{k-473} \\
(k & =0 \ldots m N-1)
\end{aligned}
$$

where $\lambda_{k}$ is the wavelength in channel $k$.

The result of this calculation is shown in figure $5 b$, where negative peaks disappear.

4.1 CALIBRATION AND D-SPACING MEASUREMENT. A very precise knowledge of the flight path length and diffraction angle is necessary to obtain the function $\mathrm{d}(h k l)=f(N)$ where $N$ is the channel number. Due to the sample and detectors sizes, $L_{0}$ and $\theta_{0}$ are difficult to measure with sufficient accuracy and the electronic time delay $t_{\mathrm{R}}$ is not known.

The best way is to calibrate experimentally the spectrometer using a test sample whose parameter is known with accuracy (silicon, germanium, diamond). 

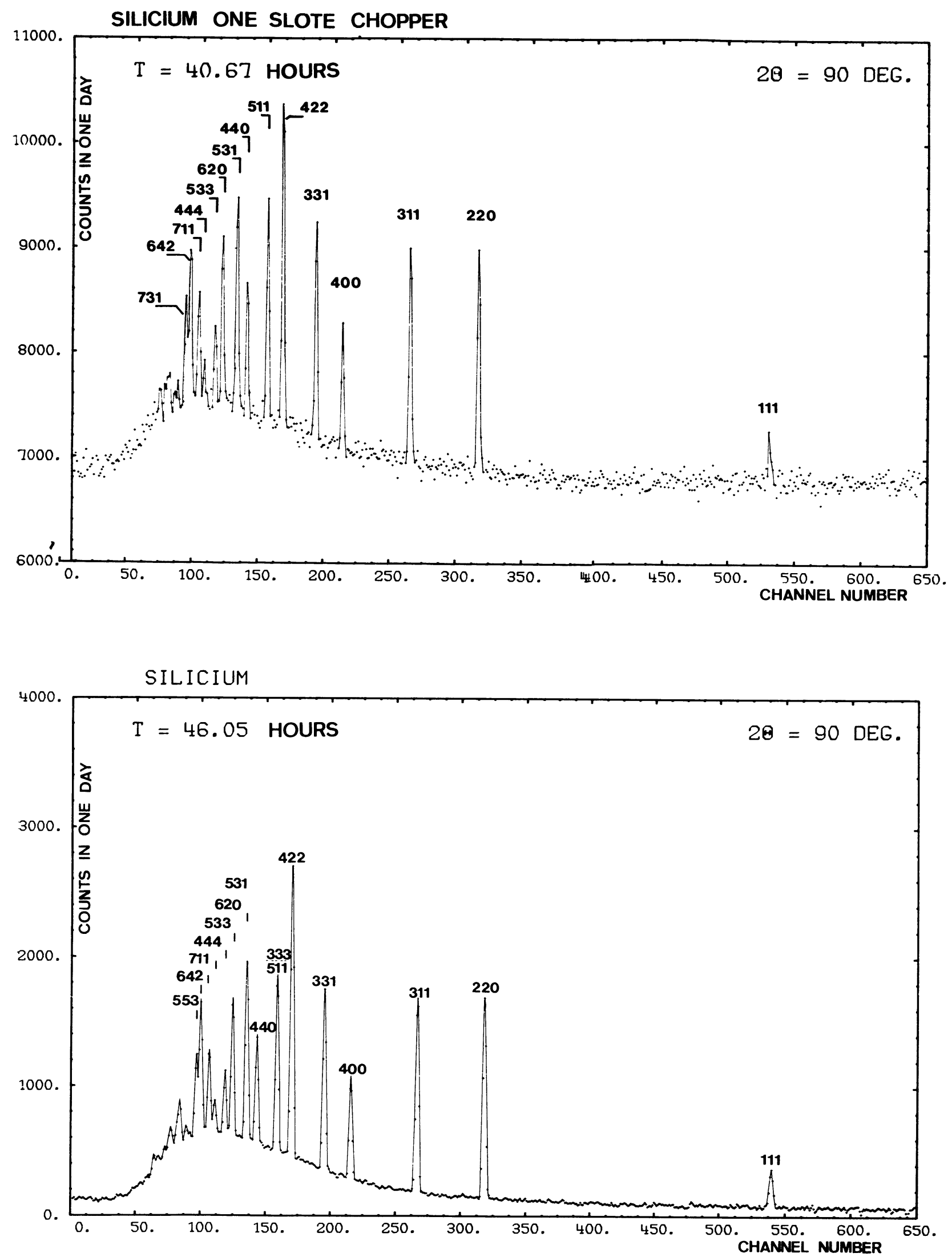

FIG. 4. - a) Silicon pattern with one slot disc. b) Silicon pattern with correlation disc. 

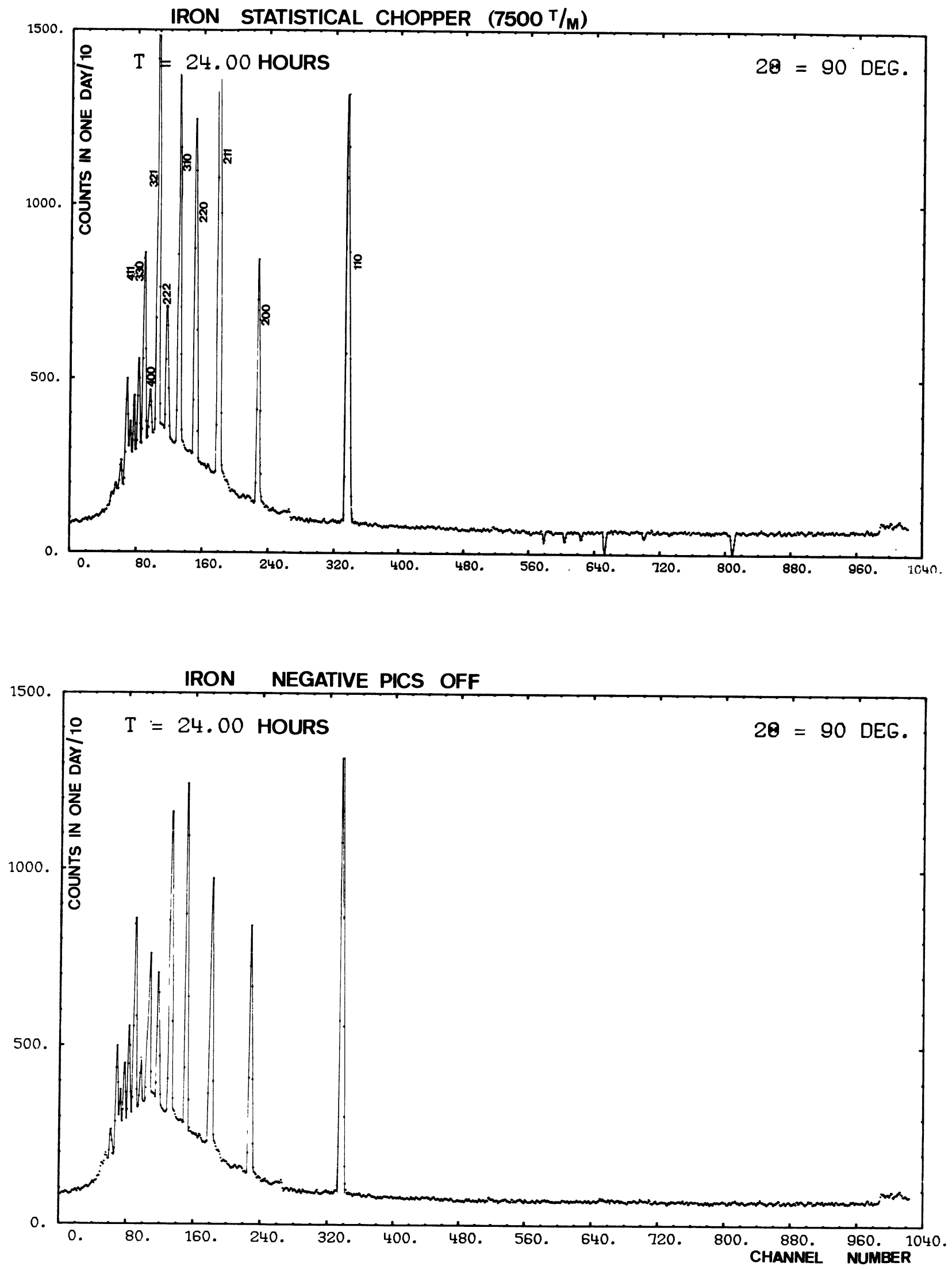

FIG. 5. - a) Iron pattern after deconvolution. Negative peaks appear between channels 560 and 820 . b) The same after correction using equation (5). 
A diffraction pattern can be represented, in a first approximation by the function :

$$
\begin{aligned}
F(d)=u & +\frac{\beta}{d^{\gamma}} \mathrm{e}^{-\delta / d^{2}}+ \\
& +\sum_{j=1}^{P} \alpha_{j} \exp \left(-\frac{4 \log 2\left(d-d_{j}\right)^{2}}{\Delta d_{j}^{2}}\right) .
\end{aligned}
$$

In this theoretical expression :

- the first term $u$ is the time-independent background,

- the second term represents the maxwellian back- ground due to the incoherent elastic scattering of the sample,

- the third term represents $P$ gaussian diffraction peaks centered in $d_{j}$ with amplitude $\alpha_{j}$ and FWHM $\Delta d_{j}$,

$-d_{j}$ and $\Delta d_{j}$ are related to channel $N$ by expressions (1) and (2) respectively.

Parameters $u, \beta, \gamma, \delta$ concerning background, $\alpha_{j}, C, t_{\mathrm{R}}$ concerning peak amplitude and position and $A, B$ concerning resolution in the expression (6) are fitted to the observed diffraction function using a program developed at Argonne National Laboratory. Tables II and III give the results of the fit, compared

TABLE II

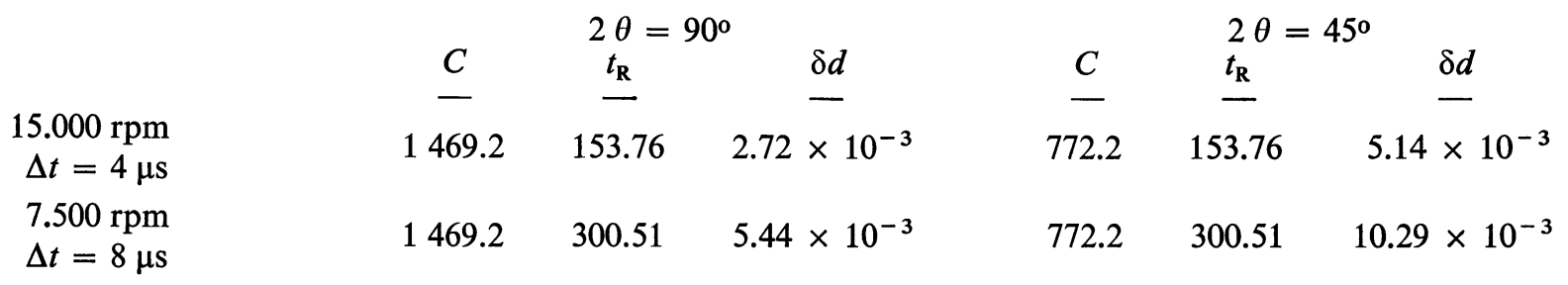

TABLE III

\begin{tabular}{lcccc} 
& \multicolumn{2}{c}{$7.500 \mathrm{rpm}$} & \multicolumn{2}{c}{$15.000 \mathrm{rpm}$} \\
& $2 \theta_{0}=90^{\circ}$ & $2 \theta_{0}=45^{\circ}$ & $2 \theta_{0}=90^{\circ}$ & $-45^{\circ}$ \\
$A^{2}$ measured & $-242 \pm 2.9$ & $331 \pm 6.1$ & $81.6 \pm 1.8$ & $74.6 \pm 7.5$ \\
$A^{2}$ theoretical & 344.45 & 344.45 & 86.11 & 86.11 \\
$B^{2}$ measured & $(15 \pm 1) 10^{-6}$ & $(76 \pm 3) 10^{-6}$ & $(16 \pm 1) 10^{-6}$ & $(82 \pm 8) 10^{-6}$ \\
$B^{2}$ theoretical & $16.56 \times 10^{-6}$ & $66.6 \times 10^{-6}$ & $16.56 \times 10^{-6}$ & $66.6 \times 10^{-6}$
\end{tabular}

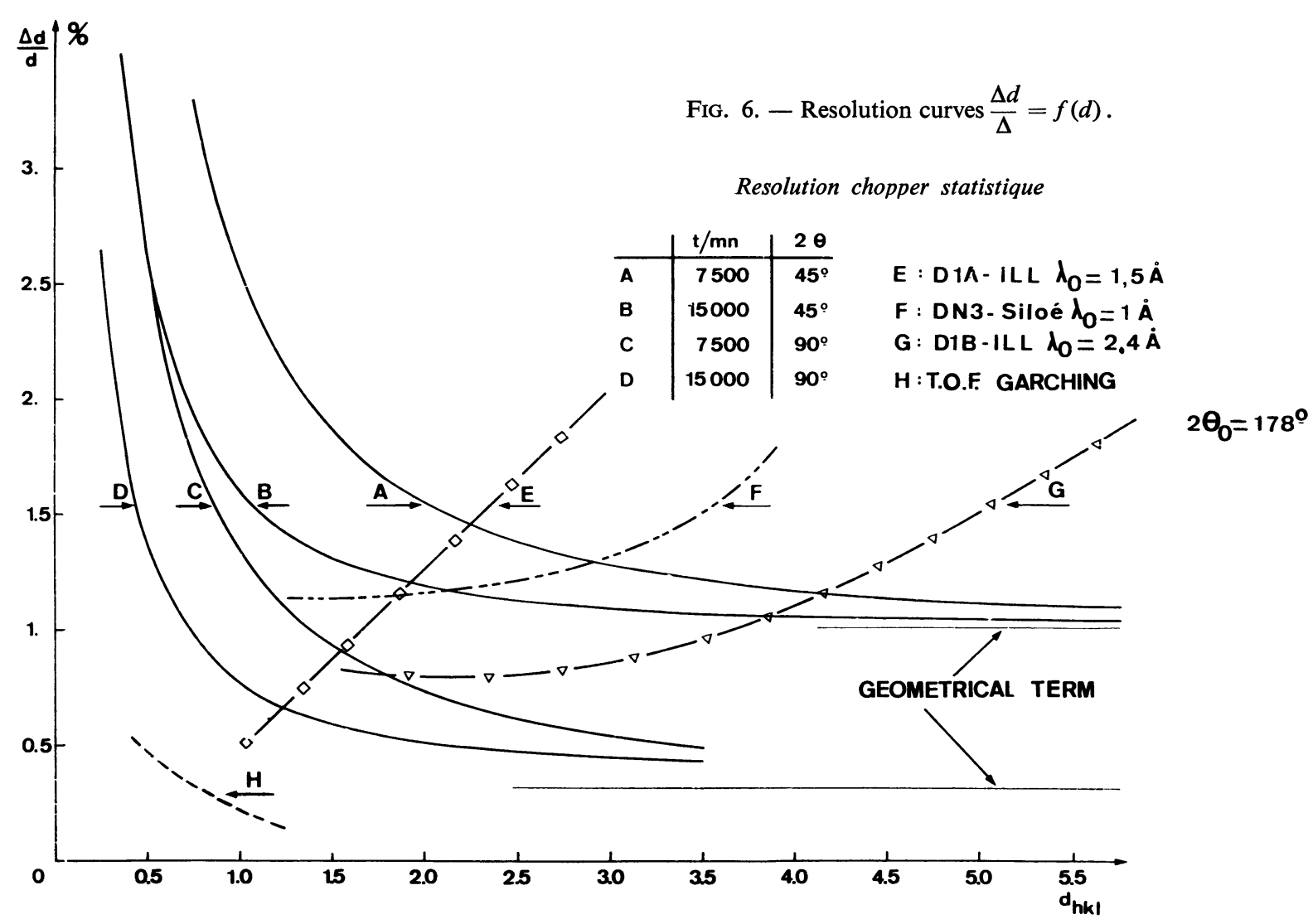


with some calculated values. Table II also gives the increase of $\mathrm{d}$ for one channel. In the best case $\left(15,000 \mathrm{rpm}\right.$ and $\left.2 \theta_{0}=90^{\circ}\right), \delta \mathrm{d}(1$ channel $)$ is $2.7 \times 10^{-3} \AA$. The peak position can be determined, by a least-square fitting of a theoretical gaussian with a precision better than $1 / 10$ of a channel. The precision of a $d$-spacing measurement is then better than $2.7 \times 10^{-4} \AA$ and allows for very precise cell parameter determination [13].

4.2 Resolution. - Table III gives the observed values for terms $A$ and $B$ of the resolution (equation (2)). They compare very well with the theoretically calculated ones, especially for the $90^{\circ}$ angle where 13 diffraction peaks of a diamond sample can be used for calibration, when only 5 are usable at $45^{\circ}$.

The resolution curves of the spectrometer are plotted in figure 6 and can be compared with those of other spectrometers. Typical values of $0.7 \%$ at $d=1 \AA$ and $0.4 \%$ at $d=3.5 \AA$ are obtained. The good resolution for large $d$-spacings (low Miller indices) allows for determination of deformed structures set off by splitting of diffraction peaks.

5. Structure determination. - In a time-of-flight experiment, the main problem to solve is the calculation of structure factors from the observed diffracted integrated intensities. The structure factors are given theoretically by :

$$
\left|F_{h k l}\right|^{2} \propto \frac{I_{0}}{j \cdot i(\lambda) \cdot \lambda^{4} \cdot A(\lambda) \cdot E(\lambda)}
$$

where the incident beam $i(\lambda)$, the sample absorption $A(\lambda)$ and the detector efficiency $E(\lambda)$ must be known accurately.

The integrated intensity if a diffraction peak is obtained by the fit of the parameters of a theoretical gaussian to the observed peaks (equation 6).

Three different methods have been used.

5.1 DiRECT FIT OF THE WHOLE OBSERVED PATTERN. In this method, a program developed at Argonne National Laboratory is used $\left({ }^{1}\right)$. The theoretical expression given in equation (6) is fitted to the observed pattern. The maxwellian background is then supposed to represent the incident beam affected by sample absorption and detector efficiency, which are not calculated separately. Therefore, this method assumes that the incident beam is maxwellian and does not take into account anomalies such as those of figure 7, which represents the pattern of the incident beam measured by means of a boron monitor. This plot is not maxwellian particularly from channels 250 to 300. This comes from absorption and diffraction in the numerous aluminium windows between the reactor core and the detectors.

5.2 USE OF THE INCIDENT BEAM MEASUREMENT. In this case the incident wavelength-dependent beam is measured by means of a boron monitor $\left(1.4 \times 10^{-4}\right.$

(1) This program is no more in use at A. N. L. and is replaced by a profile analysis program.

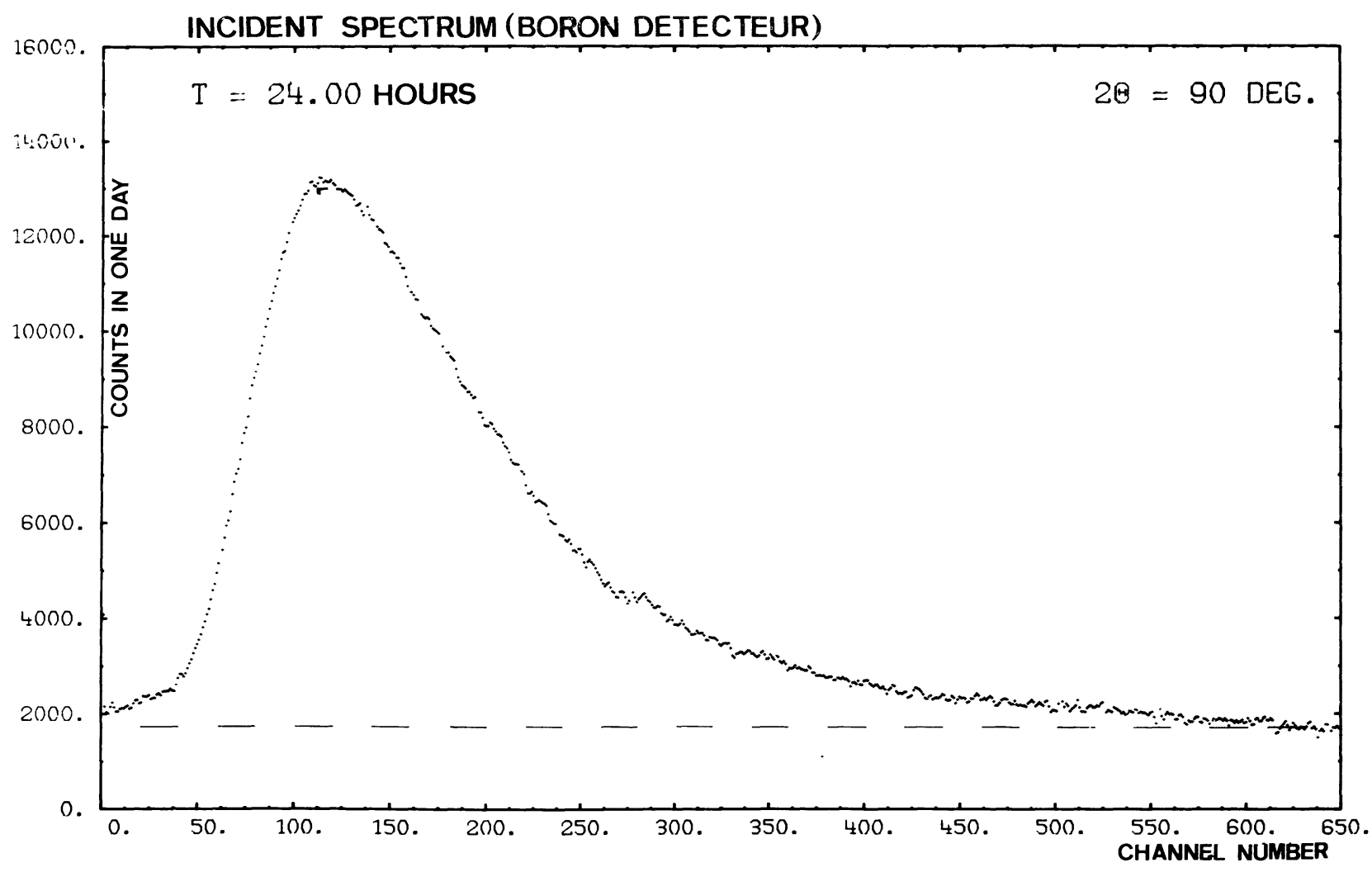

Fig. 7. - Pattern obtained with a monitor in the direct beam. 
efficiency for $\lambda=1.8 \AA$ ) and the absorption $A(\lambda)$ and the detector efficiency are calculated accurately for the two Bragg angles at $90^{\circ}$ and $45^{\circ}$. The measured pattern $i(\lambda)$ of figure 7 is calibrated by means of a copper monocrystal in reflection for planes $(2 n, 0,0)$ at the $90^{\circ}$ angle. Diffraction peaks are observed at this angle and holes correspond to them in the simultaneous measurement of the direct beam with the boron monitor behind the crystal. The direct beam pattern is corrected from the boron monitor efficiency which is proportional to $\lambda$.

The detector's efficiency is then calculated, using their theoretical geometrical setting, taking into account that they slightly overlap inside the groups of 8 , due to the large focusing angle. The calculation is performed using a Simpson method. The efficiency is defined by the following expression :

$$
E(\lambda)=1-\mathrm{e}^{-P(\lambda)}
$$

where $P(\lambda)$ is a polynomial approximation of the third order.

Finally the sample absorption is calculated by means of an approximate equation given by Rouse et al. [15].

$$
A(\lambda)=\frac{I_{\text {obs }}}{I_{\text {true }}}=\mathrm{e}^{-\left(1.6598-0.2832 \sin ^{2} \theta\right) \cdot r \cdot \mu(\lambda)} .
$$

The function $\mu(\lambda)$ is obtained, using absorption crosssections from Neutron Cross-Sections [14].

5.3 USE OF THE VANADIUM DIFFRACTION PATTERN. Vanadium scatters neutrons essentially by an incohe- rent elastic process, the corresponding cross-section (5.1 barns) being much larger than the coherent elastic one (0.029 barns). The Vanadium pattern of figure $8, i_{\mathrm{v}}(\lambda)$, is an incoherent elastic background proportional to $i(\lambda)$, with small peaks corresponding to the elastic scattering of Vanadium and Vanadium oxide :

$$
i_{\mathrm{v}}(\lambda)=i(\lambda) \cdot E(\lambda) \cdot A_{\mathrm{v}}(\lambda) \cdot \mathrm{e}^{-2 W \mathrm{v}}
$$

where $E(\lambda)$ is the detector efficiency, $A_{\mathrm{v}}(\lambda)$ is the Vanadium absorption, and $W_{\mathrm{V}}(\lambda)$ is the DebyeWaller coefficient of Vanadium.

The structure factors are then given by :

$$
\left|F_{h k l}\right|^{2} \propto \frac{I_{0} \cdot A_{\mathrm{v}}(\lambda) \cdot \mathrm{e}^{-2 W_{\mathrm{v}}}}{i_{\mathrm{v}}(\lambda) \cdot \lambda^{4} \cdot A(\lambda)} .
$$

With this method it is not necessary to calculate the detector efficiency and the calibration for Vanadium is the same as for the sample.

5.4 Discussion. - The three methods have been tested with a sample of $\mathrm{UO}_{2}$, previously studied on the high resolution fixed-wavelength goniometer D1A at Institut Laue-Langevin. Debye-Waller coefficients for Uranium and oxygen have been determined by structure refinement, the reliability factor $R$ being defined as :

$$
R=\frac{\left.\sum|| F\right|_{\text {obs }} ^{2}-|F|_{\text {calc }}^{2} \mid}{\sum|F|_{\text {obs }}^{2}}
$$

Results are summarized in table IV.

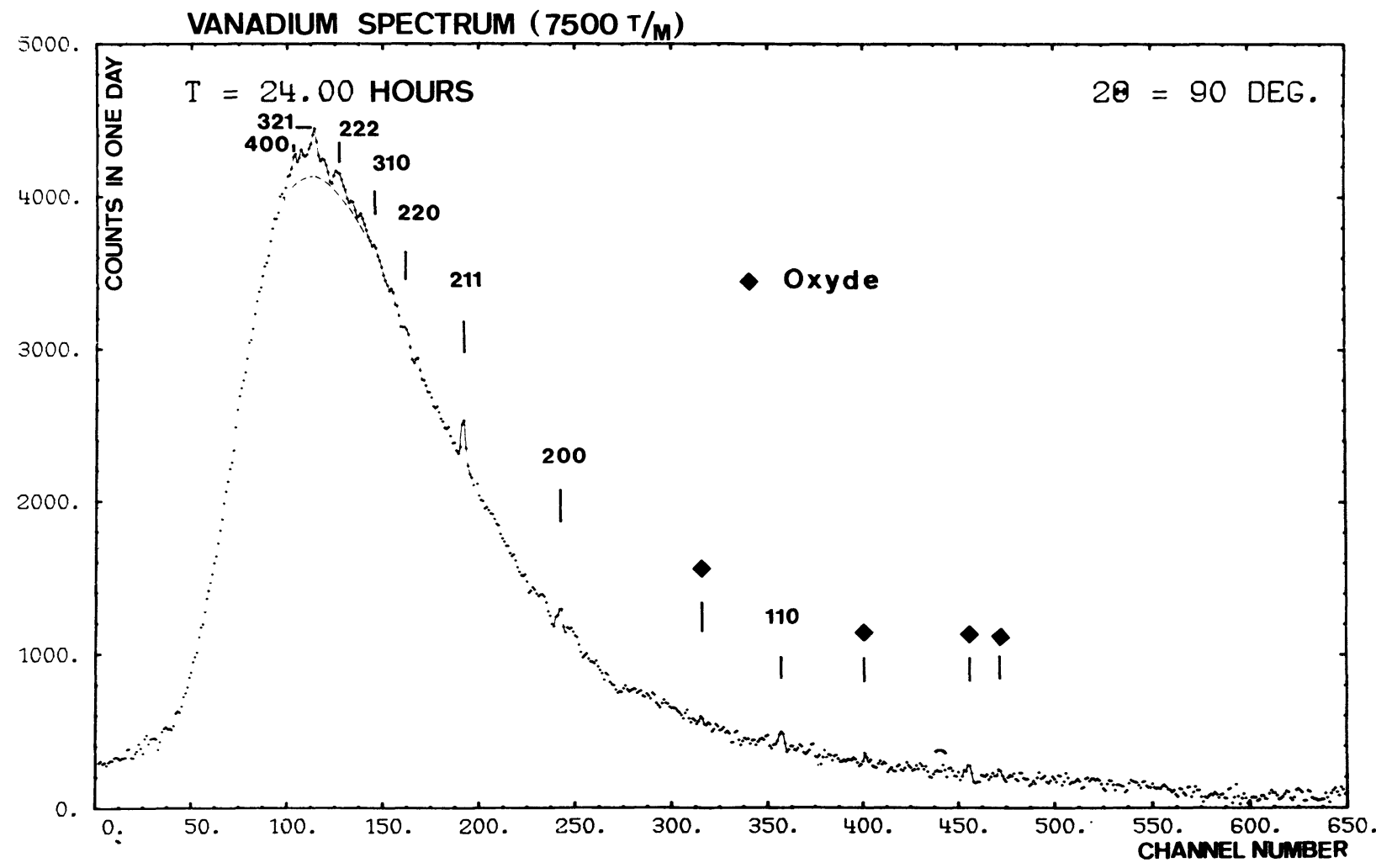

Fig. 8. - Vanadium spectrum. 


\begin{tabular}{lccc}
\multicolumn{3}{c}{ TABLE IV } \\
& $R \%$ & $B$ Uranium $\left(\AA^{2}\right)$ & $B$ oxygen $\left(\AA^{2}\right)$ \\
Direct fit & $\overline{2.2}$ & $0.41 \pm 0.13$ & $0.63 \pm 0.12$ \\
Monitor method & 1.3 & $0.01 \pm 0.05$ & $0.22 \pm 0.05$ \\
$\begin{array}{l}\text { Vanadium } \\
\text { method }\end{array}$ & 1.3 & $0.32 \pm 0.06$ & $0.51 \pm 0.05$ \\
D1A & 1.5 & $0.24 \pm 0.05$ & $0.51 \pm 0.06$
\end{tabular}

The D1A results compare very well with those of Rouse et al. [18]. The three time-of-flight methods give small reliability factors, but with large differences on the Debye-Waller coefficients.

The direct fit gives excessively large values for $B$ with large uncertainties. This comes from the use of a theoretical maxwellian incident spectrum which does not take into account the irregularities shown in figure 7. The monitor method gives $B$ values which are too small, but with small uncertainties. This could come from two causes :

a) monitor and shielding not very well adapted, giving a distorted image of the incident spectrum ;

$b$ ) use of theoretical geometrical values for the calculation of detector efficiency.

One may note that although the absolute $B$ values are wrong, the difference $[B(O)-B(U)]$ is good, and the same for the two methods.

The Vanadium method avoids the calculation of the detector efficiency and gives results comparing fairly well with those of DIA. It seems to be the best method and is now always used.

6. Auxiliary equipment. - For high temperature work, a furnace [13] heating up to $1700^{\circ} \mathrm{C}$ in an oxidizing atmosphere and up to $2500^{\circ} \mathrm{C}$ in a neutral or reducing atmosphere is used.

In high pressure work, a pressure cell has been developed allowing pressure up to 35 kbars. For magnetic phase studies, it can be cooled down to $4.2 \mathrm{~K}$ in a special cryostat [16], [17].
7. Conclusion. - When the sample surrounding gives rise to intense diffraction peaks, which overlap with those of the sample, the time-of-flight spectrometer is much more adapted than the fixed wavelength goniometers. Its good resolution allows for high accuracy thermal expansion [13] and compressibility measurements, and can emphasize structure deformations.

The first refinements of simple structures give reliability factors between 1 and $2 \%$, very much better than those obtained with most of the other elastic time-of-flight spectrometers on continuous reactors, even when the samples are submitted to high temperature [13]. On the other hand, some difficulties appear for absolute Debye-Waller coefficient determination. Indeed, the spectrometer resolution and statistical accuracy require a perfect knowledge of the wavelength dependence of detector efficiency and of the incident beam. The Vanadium method is the best one, but may be improved.

Then other shapes for the diffraction peaks must be looked into, and the composition of the maxwellian background, even for Vanadium, must be studied. Thermal diffuse and multiple scattering corrections have not been considered.

Acknowledgments. - The authors wish to thank T. G. Worlton and D. L. Decker from Argonne National Laboratory for providing copies of several programs, and for their help during the stay at Argonne of one of US (G. R.). They wish to thank A. Hewat of Institut Laue-Langevin for providing results on $\mathrm{UO}_{2}$. They gratefully acknowledge the technical staff of C. E. N. Grenoble, especially J. Bost (SAPTA) for the mechanical part, J. L. Lecompte, B. Thevenin, D. Ruquet, C. Favier, Y. Didier (L. E. T. I.) for electronics, and the Melusine Reactor staff for their help during the construction of the spectrometer.

\section{References}

[1] Brugger, R. M., Bennion, R. B., Worlton, T. G. and Peterson, E. R., Panel on research applications of nuclear pulsed system. I. A. E. A., Vienna, STI/PUB/144, PL 203 (1967) 35.

[2] Worlton, R. G., Ph. D. Thesis, Brigham Young University.

[3] Buras, B., Neutron diffraction conference, Petten (1975).

[4] GompF, F., Reichardt, W., Gläser, W. and BeckUrtZ, K. H., Neutron inelastic scattering, vol. II, I. A. E. A., Vienna (1968) 417.

[5] SKöLD, K., Nucl. Instrum. Meth. 63 (1965) 123.

[6] Buevoz, J. L. and Roult, G., Use of a correlation chopper for time-of-flight Neutron Scattering. Part I. - Theory of the Deconvolution (to be published).

[7] Buevoz, J. L. and Roult, G., Use of a correlation chopper for time-of-flight Neutron Scattering. Part II. - Deconvolution in the experimental case (to be published).

[8] Burvoz, J. L., Thèse pour le grade de Docteur es-Science, No AO 11644 (1975) Université de Grenoble, France.
[9] Buras, B. and Holas, A., Report INR No 745/II/PS.

[10] Holas, A., Report INR No 742/II/PS.

[11] BurAs, B., Nukleonika 8 (1963) 259.

[12] Gobert, G., Internal Report, Service de Physique du Solide et de Résonance Magnétique. CEN-Saclay, France.

[13] Aldebert, P., Badie, J. M., Traverse, J. P., Buevoz, J. L. and Roult, G., Rev. Int. Htes. Tem. et Refract. 12 (1975) 307.

[14] B. N. L. 325, Neutron cross-section.

[15] Rouse, K. D., COPPER, M. J., York, E. J. and ChaKera, A., Acta. Cryst. A26 (1970) 682.

[16] Roult, G. and Buevoz, J. L., 5th International Conference on High-Pressure and Technology (Moscou) 1975.

[17] Claudet, G., Disdier, F., Senet, L., Buevoz, J. L. and Roult, G., Rev. Sci. Instrum. 45 (3) (1974) 341.

[18] Rouse, K. D., Willis, B. T. M. and Pryor, A. W., Acta Cryst. B24 (1968) 117. 